\title{
PRÓTESE INTRACAVA PROVISÓRIA NO TRATAMENTO DE LESÃO DA VEIA CAVA RETRO-HEPÁTICA
}

\section{TEMPORARY INTRACAVAL PROTHESIS IN TREATMENT OF RETROHEPATIC VENA CAVA INJURY}

\author{
Dalmer Faria Freire, ACBC-SP ${ }^{1}$ \\ Gilberto Lopes Gonçalves ${ }^{2}$ \\ Márcia Vrigério Alcarde ${ }^{3}$
}

\section{INTRODUÇÃO}

Com o crescimento da violência urbana houve aumento exponencial dos ferimentos por arma de fogo e arma branca na população civil. Estes ferimentos, quando incidem no abdome, produzem os mais variados tipos de lesões em estruturas e órgãos intracavitários, entre as quais se encontram as lesões da veia cava inferior. Estas lesões são importantes pela sua gravidade e alta letalidade quando não tratadas rápida e adequadamente ${ }^{1}$.

Dentre as lesões mais desafiadoras para o cirurgião destacam-se as da veia cava retro-hepática (VCRH) pela dificuldade no controle do sangramento bem como no isolamento da região. A hipovolemia e a presença de lesões associadas, geralmente presentes nestes casos, tendem a agravar ainda mais o quadro destes pacientes ${ }^{2}$. A opção por tratar todas as lesões (vasculares e associadas) numa única intervenção geralmente leva a acréscimo significativo no tempo cirúrgico, com conseqüente aumento da morbidade e mortalidade trans e pós-operatórias.

Como alternativa de tratamento para estes doentes tem sido utilizada a prótese intracava sem abordagem direta do ferimento vascular, com retirada da mesma num segundo tempo operatório ${ }^{3}$. A utilização deste procedimento nos motivou a apresentar este caso.

\section{RELATO DO CASO}

M.S.O., masculino, 27 anos, deu entrada no Setor de Emergência do Hospital Municipal do Campo Limpo vítima de ferimento por projétil de arma de fogo ocorrido há cerca de 12 horas. O orifício de entrada localizava-se no $8^{\circ}$ espaço intercostal esquerdo, linha mamilar. Não havia orifício de saída, porém o projétil era palpável no $4^{\circ}$ espaço intercostal direito, linha axilar posterior. O doente estava consciente, descorado ++/4+, PA de 100x60 mmHg, FC de $110 \mathrm{bpm}$, com abdome tenso e doloroso à palpação e com descompressão brusca dolorosa.

Realizou-se drenagem torácica bilateral, venóclise com tipagem sangüínea e infusão de $2.000 \mathrm{ml}$ de solução cristalóide, sendo o doente encaminhado ao Centro $\mathrm{Ci}$ rúrgico. À laparotomia encontrou-se laceração dos segmentos hepáticos I, II e III com pequeno sangramento ativo e orifício em região retro-hepática provocado pelo projétil. A exploração deste ferimento deu início a sangramento profuso. Foi realizada, então, a oclusão da tríade portal (manobra de Pringle) utilizando-se uma pinça de Satinski. A seguir a incisão foi ampliada para toracofrenolaparotomia direita quando foram constatadas lesões na veia supra-hepática esquerda, na veia cava inferior ao nível da terminação da veia supra-hepática esquerda, e na VCRH cerca de $1 \mathrm{~cm}$ distalmente a estas lesões. Como o paciente evoluiu para choque hipovolêmico no transoperatório, optou-se inicialmente pela introdução de dreno de tórax no 36 na veia cava pela perfuração retro-hepática desta veia. $\mathrm{O}$ tubo foi fixado por fita cardíaca envolvendo a veia cava intrapericárdica e a VCRH $1 \mathrm{~cm}$ abaixo da lesão distal. A seguir a veia supra-hepática esquerda foi ligada. As lesões da veia cava não foram suturadas. As lacerações hepáticas foram tratadas por rafia.

No pós-operatório o paciente foi mantido com 30.000 UI de heparina sódica a cada $24 \mathrm{~h}$, em infusão contínua.

A evolução após esta cirurgia foi satisfatória, sendo o paciente reoperado no sexto dia pós-operatório para retirada do tubo intracava. Retiradas às fitas cardíacas colocadas na cirurgia anterior observou-se ausência de sangramento retro-hepático. Como medida de segurança para impedir o sangramento após a retirada do tubo, o seg-

1. Médico Assistente de Clínica Cirúrgica, Serviço de Cirurgia Geral do Hospital Municipal do Campo Limpo; Preceptor de Cirurgia da FMUNISA.

2. Cirurgião Vascular; Médico Assistente de Cirurgia Vascular, Serviço de Cirurgia Geral do Hospital Municipal do Campo Limpo.

3. Residente de Cirurgia Geral, Hospital Municipal do Campo Limpo.

Recebido em 07/01/2002

Aceito para publicação em 11/06/2002

Trabalho realizado no Serviço de Cirurgia Geral do Hospital Municipal do Campo Limpo, São Paulo - SP (Chefe: Prof. Dr. Jorge Salles Guimarães) 
mento intrapericárdico da veia cava foi envolvido com cadarço, sendo em seguida pinçado seu segmento infra-hepático. O tubo foi então retirado da veia cava através de pequena cavotomia feita acima da pinça distal. Verificouse que o mesmo estava trombosado. Também não ocorreu sangramento pela cavotomia.

O doente teve boa evolução pós-operatória e recebeu alta 14 dias após a segunda operação.

\section{DISCUSSÃO}

Os ferimentos de VCRH são de difícil tratamento devido ao acesso laborioso e porque se acompanham, em grande número de casos, de lesões associadas graves. Se as condições clínicas do paciente o permitem, todas as lesões devem ser tratadas primariamente. Instalando-se o choque no transoperatório, porém, o quadro muda de figura drasticamente. Qualquer demora adicional tende a piorar o estado do doente, com aumento da morbidade e mortalidade.

O tratamento clássico das lesões da VCRH inicia-se com um acesso amplo obtido por meio de toracofrenolaparotomia direita. Procede-se ao pinçamento do hilo hepático e a mobilização do ângulo hepático do cólon a qual facilita a compressão do segmento da veia cava infra-hepática supra-renal para diminuir o sangramento ao nível da lesão. O pericárdio é aberto longitudinalmente. A veia cava inferior é cadarçada em seus segmentos intra-pericárdico e infra-hepático supra-renal e um tubo calibroso, geralmente um dreno de tórax n. 36 , é inserido no interior deste vaso através de uma atriotomia. $\mathrm{O}$ tubo é fixado dentro da veia cava por meio dos cadarços previamente posicionados. $\mathrm{O}$ bypass atriocaval assim instalado irá possibilitar o tratamento das lesões da VCRH sem prejuízo do débito cardíaco ${ }^{4}$.No presente caso, entretanto, a visão direta do ferimento da veia permitiu que o tubo fosse introduzido pelo próprio orifício encontrado.
A abordagem da VCRH usualmente é feita pela luxação do lobo direito a qual se obtém pela secção do ligamento triangular direito e ampla rotação lateral esquerda do mesmo, permitindo a exposição e reparo das lesões. Outras alternativas de acesso são a lobectomia direita ou esquerda, bem como as segmentectomias médias anteriores ${ }^{5}$. Estas últimas são manobras trabalhosas que acrescentam considerável trauma e tempo adicional ao ato cirúrgico, o que, no enfermo em choque hipovolêmico como o do caso apresentado, podem contribuir para o óbito.

$\mathrm{O}$ cadarçamento prolongado da veia cava acima das veias supra-hepáticas bloqueia o aporte de sangue portal, podendo desencadear graves consequências para o doente. A boa evolução neste caso ocorreu provavelmente pela existência de satisfatória rede de vasos colaterais.

No nosso caso, a cavotomia exangue sugere ter ocorrido a trombose da veia cava no seu segmento retro-hepático a qual não pôde ser comprovada por cavografia devido à inexistência do equipamento para este exame no hospital. A trombose da veia cava inferior deveria, se presente, acarretar dificuldade do retorno venoso dos membros inferiores traduzida por edema, o que não foi constatado no pós-operatório imediato. Acreditamos que a circulação venosa portal deste paciente não foi prejudicada pela ligadura da veia supra-hepática esquerda devido à existência de veias colaterais.

$\mathrm{O}$ presente relato demonstra opção técnica que se mostrou efetiva. O desvio do fluxo venoso do sítio da lesão propiciou condições para a formação do coágulo e hemostasia da mesma. Isto tornou desnecessária a rafia do ferimento também na segunda intervenção cirúrgica, embora o doente já reunisse condições clínicas para tratamento mais complexo, se necessário.

Este resultado nos estimula a realizar estudos experimentais do procedimento. Acreditamos, entretanto, ser esta uma boa alternativa a ser considerada diante de casos semelhantes.

\begin{abstract}
One of the most difficult challenges to surgeons is the treatment of wounds on the retro hepatic vena cava. The anatomic particularities of this venous segment make its approach and treatment difficult, contributing to a high morbidity and mortality. Several techniques have been described for the treatment of these types of lesions. In this particular case, authors have chosen the introduction of a fastened provisory intra caval prothesis, without primary suturing of the wounds. The provisory intra caval prothesis can be an option for the treatment of retro hepatic vena cava lesions.
\end{abstract}

Key Words: Vena cava injury; Retro hepatic vein trauma.

\title{
REFERÊNCIAS
}

1. Nance FC, Wennan MH, Johnson LW et al. Surgical judgment in management of penetrating wounds of the abdomen: experience with 2212 patients. Ann Surg 179:639, 1974

2. Weichert RF III, Hewitt RL. Injuries of the inferior vena cava. Report of 36 cases. J Trauma 10:649, 1970.

3.Burch JM, Feliciano DV, Mattox KL et al. Injury of the inferior vena cava. Am J Surg 156:548, 1988.

4. Burch JM, Feliciano DV, Mattox KL. The atriocaval shunt. Facts and fiction. Ann Surg 207:555, 1988.
5. Iwasaki Y, Okamura T, Ozaki A. Surgical treatment for carcinoma at confluence of the major hepatic ducts. Surg Gynecol Obstet 162:457-464, 1987.

Endereço para correspondência:

Dr. Dalmer Faria Freire

Rua Nebraska 53, apto. 52

04560-010 — São Paulo-SP 